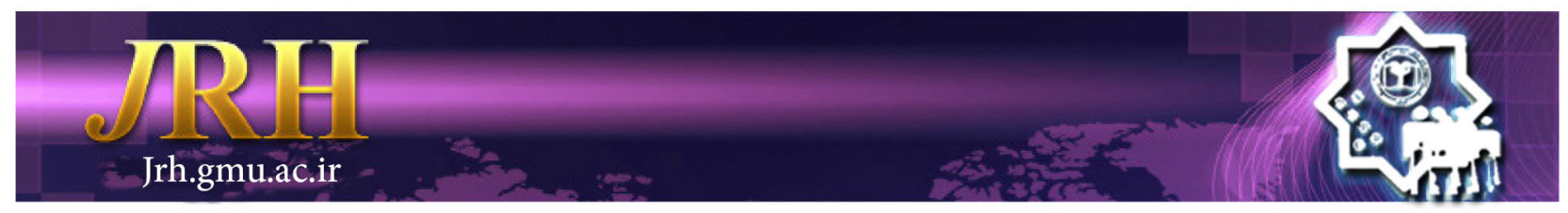

\title{
The experience of pregnancy in women with high body mass: a hermeneutical/phenomenological study
}

Samira Shahbazzadegan ${ }^{1}$

Journal of Research \& Health

Social Development \& Health Promotion Research Center

Vol. 9, No.2, Mar \& Apr 2019

Pages: 147- 155

DOI: $10.29252 / j r h .9 .2 .147$

Original Article

1. Correspondence to: Department of Midwifery, School of Nursing and Midwifery, Ardabil University of Medical Sciences, Ardabil, Iran

Email: samirashahbazzadegan2000@yahoo.com

Received: 5 May 2017

Accepted: 2 Dec 2017

How to cite this article: Shahbazzadegan S. The experience of pregnancy in women with high body mass: a hermeneutical/ phenomenological study. $J$ Research \& Health2019; 9(2): 147- 155.

\begin{abstract}
Overweight is one of the most common health problems and risk factors for many prenatal illnesses. The proportion of pregnant women with high body mass would be increased by increasing body mass in society. The purpose of this study was to explain the pregnancy experience in women with high body mass index. An interpretive phenomenological approach was used to conduct this study. Participants included ten pregnant women with high body mass index who were interviewed. All interviews were recorded and transcribed after permission from the participants in order to explain the phenomenon under study and the data were analyzed by using the Van Manen method in MAXQDA version-10 software to emerge their themes and their basic patterns. Out of the 857 extracted primary codes, the experience of women with high birth weight was summarized in the main theme of "Pregnancy concurrent with concern". This theme comprised the following subthemes: "sense of risk", "lack of care facilities for mothers with high body mass index", "obesity as a stigma", and "lack of specialized care". This Hermeneutic phenomenology study showed that pregnant women with high body mass are a vulnerable group. Their pregnancy concurrent with more concern requires more care and support. Service providers, in particular midwives, nurses, and doctors, should be aware of their attitudes and behaviors toward this group of clients and avoid any stereotypical and harassing care behaviors.
\end{abstract}

Keywords: Experiences, Overweight, Pregnancy, Qualitative Study, Women

\section{Introduction}

Overweight or high body mass is one of the serious health problems and risk factors for many diseases during pregnancy. World Health Organization (WHO) has described obesity as one of the major health problems in many countries and introduced it as an epidemic disorder [1]. A study conducted in the Mediterranean Basin showed that the prevalence of obesity was higher in urban areas; a trend that is expected to observe in Iran [2]. The fact of the increasing prevalence of obesity in Iran and in the world is the reason for considering it as a particular disease. Until the end of the second world war, people in the world suffered more from underweight, due to lack of industrial facilities and food shortage. At the end of this period with the development of countries, mechanization of life, the growth of 
food production and its availability throughout all seasons and low physical activity of people, the problem of overweight and obesity increased. The elimination of many infectious diseases through vaccination, the improvement of health and, consequently, the aging of people, and the lack of mobility due to age are other causes of the prevalence of obesity in the world. Obesity is one of the most common noncommunicable diseases in Iran [3]. The number of overweight people in developing countries has approximately quadrupled between 1980 and 2008. Regarding gender differences in obesity, it should be noted that the phenomenon of high body mass and overweight is more common in women than in men. The study of Emamian et al. in Tehran showed that the prevalence of obesity is increasing rapidly in the age of 20-40 years [4].

Concerning the distribution of obesity in the provinces of Iran, it should be mentioned that most provinces are involved in the problem of obesity. A lower prevalence of obesity is observed in some provinces, such as Sistan and Baluchestan, while the provinces of Tehran and Markazi are seriously affected by this problem [5-7].

As obesity increases, the proportion of high body mass women who experience pregnancy also increases, while no evidence is available regarding their experience and needs. In the United States, more than a third of women and over half of the pregnant women are obese or overweight, and eight percent of women with obesity are extremely obese that can expose them to high-risk pregnancy. Pregnant women with overweight and high body mass are at risk of various complications of pregnancy, including abortion [8], congenital anomalies [9], thromboembolic events [10,11], gestational diabetes [12], high blood pressure and preeclampsia [13], labor pain complication [14], bleeding after delivery [12], cesarean section delivery, postpartum weight stability [2-12], wound site infection [12], complications due to anesthesia [15], stillbirth [16-17], and the death of infant [18-19]. Higher complications during pregnancy induce adverse outcomes during labor and postpartum depression [20]. Even the inclination to start and continue breastfeeding is less in women with high body mass than in other mothers [21,22]. Along with all the physical abnormalities of the disease, the illness greatly affects their mental health [20]. Evidence suggests that high Body mass index (BMI) causes an increase in maternal mortality. It has been shown that $28 \%$ of mothers who died had a high body mass in a study over a three-year period, while this rate in mothers with a normal weight was 16-19 percent [23-24].

Any successful planning and intervention depends on factors such as approaching the clients through conducting depth interviews, discovering their emotions and attitudes to self-image, illness, etc., and ultimately, their motivation to follow-up and involvement in the desired actions [25]. If suggestions and plans for people with high body mass are in accordance with the experience and beliefs of people who live with this phenomenon, they can be more useful and realistic compared to recommendations solely based on the opinion of professional people. If healthcare providers understand how pregnancy complications are in women with high body mass, based on their real and life-related experiences in their everyday lives, it will reach them to a deep and real understanding to guide them appropriately in their decisions, interventions, and actions. The value of discovering such experience has been accepted for health service providers, because of the nature of the problem (the way in which one person perceives and experiences the phenomenon) highly affects the design of their care.

Since it is not possible to describe life experiences and meaningful experiences of pregnant women with high body mass through quantitative methods [26], this research was designed qualitatively. Limited information exists about the experience of pregnancy in women with high body mass in Iran, which emphasizes the relevance of conducting this research in our country's social and cultural context. Regarding the varying experience 
of pregnancy in women with high body mass, encouraging these women to express their pregnancy experience and giving them the opportunity to discuss pregnancy emotions is very important in improving their health status. Therefore, this study was conducted to explain pregnancy experience in women with high body mass index.

\section{Method}

The study setting was mother and child health care centers in Ardabil city in Northwest of Iran. Proposal of study was approved in Ardabil University of medical Sciences (ID project 9312). Data were collected over eight months from April 2015 to January 2016. In this phenomenological study, after obtaining permission for the project, the participants entered the study by targeted sampling method according to the purpose of the study to obtain the mental conception of pregnancy in women with high body mass.

Participants comprised women who were in the last months of their pregnancy and had a body mass index higher than 30 before pregnancy (According to the WHO definition, the people with BMI over 30 are obese). They had a single pregnancy, were aged 18 years old or more, had the ability and the possibility for proper communication, and were able to provide rich and complete information to the researcher. After obtaining consent from the participants, semi-structured interviews were conducted with questions such as; what is your experience with this pregnancy. Describe one day. The access place to attendees was the health centers affiliated to Ardabil University of Medical Sciences. After obtaining a research license, the researcher referred to the health centers with a referral letter, selected the participants according to the inclusion criteria and then, by expressing the purpose of the research and obtaining informed consent from the participants, interviews were conducted in a relaxed and participatory manner at any place that they determined. During the interview, the observation and recording took place. The mean length of the interviews was about 50 minutes. Audio files were instantly converted to text files. Interviews continued until the richness of the data when no new data emerge compared to the last interview. At the end of each interview, a report was made on anything that could be taken into consideration in the analysis regarding, for example, how the interview process was and what the important points were. The van Manen's method was used for the study [27]. Finally, 10 pregnant women completed the interviews. The researcher's activity was based on van Manen suggested 6 steps. The steps of van Manen's method include referring to the phenomenon/ experience of the study, the serious inspiration of the researcher's interest to the subject, exploring the experiences of the collaborators and avoiding the conceptualization of data, contemplating the intrinsic content that describes the phenomenon, describing the phenomenon through art writing and rewriting, maintaining strong and targeted relationship with the phenomenon studied and balancing the research context with the continuous consideration of the relationship between the components and the whole. Initial data the analysis was performed using MAXQDA version 10 software.

Based on the commonality for quality assurance in qualitative research, the researcher tried to maintain the validity, reliability, transferability, and verification criteria to improve the quality of research [27]. Checking by contributors was done frequently to ensure the accuracy and reliability of the data in a long-term and continuous engagement, by using maximum variation in sampling, and holding integration in research and review. Also search for conflicting evidence was used. The study was conducted with the observance of all ethical issues.

\section{Results}

Participants included 10 pregnant women with high body mass index who referred to Ardabil health centers. The mean age of mothers was 32 years. Seven of them were 
housekeepers and three were employees. Mothers' level of education varied from literacy to university education. The mean body mass index of mothers before pregnancy was 33 . During the interaction between the researcher and the participants, the considered reality of "mental meaning of pregnancy in women with high body mass" was identified. From the contributions of participants, 857 primary codes were obtained. The main theme and subthemes of pregnancy experience of women with a high body mass that extracted after analysis of this primary codes are presented in Table 1.

Table 1 Themes and subthemes of pregnancy experience in women with high body mass

\begin{tabular}{cc}
\hline \multirow{2}{*}{$\begin{array}{c}\text { Pregnancy concurrent } \\
\text { with concern }\end{array}$} & Sense of risk \\
\cline { 2 - 2 } & Lack of care facilities for mothers with high body mass \\
\cline { 2 - 2 } & Obesity as a stigma \\
\hline
\end{tabular}

Sense of risk: Mothers' statements showed that pregnancy induced anxiety and expectation in mothers and exacerbated their sense of risk, as a mother said: "My body weight was high, I said: now, in pregnancy my body weight will increase ten to twenty kilos, and if this weight will be fixed, can be very bad, it is hardly imaginable, but anyway, I should have a baby" (Participant 6, 29-years-old with body mass index 34). A mother said about her concern about pregnancy: "I was very worried about my obesity in the hospital, but what I must do? Because, I had to endure, I am very worried because they scared me and told that my womb will not get back after delivery, and you will have bleeding or you can't give birth. You get an infection and like this" (Participant 9, 29-years-old, with BMI 34). Another mother said: "I'm afraid the child has problems. Because, I heard that obesity of mothers affects the child, if something happens to my child, what can I do? This is my fault, $\mathrm{O}^{\prime}$ God. Obesity is worse than any pain. It is so bad, much more than you think". (Participant 1, 30-years-old with BMI 34).

Lack of care facilities for mothers with high body mass: The lack of care facilities for people with high body mass index was one of the mentioned problems among high BMI mothers. The third participant said (34-yearsold with BMI 33): "none of the doctors accepted my cesarean section in the hospital. They all passed me to another. After a few days waiting in the hospital, when they wanted to take me the operating room, the operating clothes were small for me, and I had to wear two dresses. In the operating room, I heard that the doctors told each other, the bed is breaking now". Another participant also said: "People should consider persons like me. I went to some clinics, there was no decent environment for my condition; for example, because of my situation, I want a comfortable armless chair. It is much easier for me to sit on the bench. But no chair was there" (Participant 8, 29-yearsold with BMI 34). "I had an overweight friend. Because of a problem, she has to be hospitalized in the women's ward. She was not accustomed to bed, because of her weight. In the hospital, she asked the doctors and nurses to put guards on her bed. But nobody listened to her, and at night, when she was asleep, she fell from the bed and hit her brain and died. Although this bad luck person warned before, nobody cared about her. Nobody cares about our situation". (Participant 9, 32 years-old, BMI 34).

Participants' discussions also indicated that adequate care is not usually considered for mothers with high body mass. One participant said: "When the nurse tried to take my blood pressure in the hospital, the cuff was not blocked around my arm, and the nurse looked at me sharply and wrote something by herself and went. I could not ask how my blood pressure is?" (Participant 2, 37-years-old, BMI 34).

Obesity as a stigma: The deepening in the mothers' talk showed that mothers with a high body mass index believed that they were often humiliated. It was found that they suffered 
from many cultural and social misconceptions. For example, an educated mother said, "The community looks bad for obese people. So that, even a taxi does not take us, mostly they escape from fatty people" (Participant 2, 37-years-old with BMI 34). A mother said, "Peoples looks and talks tell a lot of things about us. Obese people are considered as irresponsible and lazy people" (Participant 8, 29-years-old with BMI 34). Another participant said: "I have no problems with obesity and I compromise me with it, but only I cannot tolerate the taunting and blame of the people" (Participant 7, 28years-old, BMI 33).

Most mothers with a high body mass index believed that they were judged for their weight. Another mother said in this regard, "When I talk about something, nobody listens to me. Because, they say if you could, you controlled yourself not to fall to this situation. While I have no fault. I'm trying to lower my weight but I can't" (Participant 2, 37-years-old with BMI 34). "When I went to the hospital, doctors and nurses did not say my name, they said that Obese. Well, I became sad, but I could not say anything" (Participant 10, 33-years-old with BMI 34).

Lack of specialized care: The lack of specialized care is another subtheme of pregnancy associated with concern. Mothers' talk was full of words about the lack of specialized care. Health care providers can be confused in dealing with people with high body mass, as they have been trained to deal with ordinary people with stereotypical care for all of their clients. In some cases, mothers with high BMI require special care and education. This is usually neglected by the medical staff. One participant said in this subject: "If any problem I have, now, I go to the doctor. The doctor says "you are obese and you should reduce your weight" without any examination, cause, or words," Well, I know I am fat, but now, what can I do? They don't pay attention". (participant 4, 35-yearsold with BMI 34). The fourth participant said: "I was very thin and delicate first, I used some drugs for my infertility, and the drugs made me so and now, I say that obesity is the worst pain, worse than any disease you think. If you get cancer, everyone says you are ill and will help you, but when they see you are obese, they don't help or even make you fun" (Participant 4, 35 years-old, with BMI 34). Another woman said: "I understand that doctors are evading my admission because of my weight" (Participant 1, 30- years-old with BMI 34).

\section{Discussion}

This study was conducted with the aim of understanding the experiences of pregnant women with high body mass. Their experiences were summarized in the main theme of "pregnancy concurrent with concern". Participants described their sense of risk and inadequate and unsuitable care as their stories explained that the healthcare service offered to this group not only was insufficient, but also, in some cases, was fewer than that of other women. Health care providers did not distinguish between people with high and normal BMI and offered the same cares for both groups. Meanwhile, women with high body mass index need more interventions and support in order to facilitate the environment, nutrition, and weight control, and staff should provide cares with a useful and non-judgmental information approach. However, there is a lack of adequate knowledge about the problems in women with high body mass, which is consistent with the findings of Katherine et al., who referred to the lack of knowledge about mother and infant problems in women with high body mass [28]. Atkinson et al showed that care providers should have a new insight into complications of women with high body mass [29]. As shown in a study, women with high body mass index (BMI) should be treated differently, because of the presence of leptin antagonists during childbirth and labor [30]. Appropriate training in this group of women and increased general information can improve the mother weight control the health of babies [31]. Mothers' narratives in this study indicated the deficiency of facilities for this group of women. In this regard, equipping the health centers, especially the women's 
section, with facilities adapted to their needs, such as a convenient barometer cuff, large scale armless chairs, large wheelchairs, and large beds with fences in the sections, labor room, ultrasonography, and operating room, as well as suitable clothing and goggles, and suitable spines for spinal anesthesia and epidural is necessary.

Blind care was the other cause that harassed mothers with high body mass. Several studies showed that the behavioral orientation of health care personnel, including physicians and nurses, toward patients with high body mass index, affected the quality of care of these people [32]. In a recent study, the main reason for avoiding doctors from the cesarean section of high BMI mothers might be maternal and fetal complications due to the higher risk of cesarean for the mother and adverse birth defects. Mothers with high body mass in this study also needed to receive services without any judgments about their weight. These findings are consistent with the findings of Mahnhirin et al that examined the existence of stigma of both patient and care provider's perspective, showing that women with higher BMI had more negative experiences in pregnancy care then women with lower weight had and care providers also reported that women with high BMI had fewer self-care behaviors. They concluded that there is a weight stigma in Australian pregnancy care centers [33]. The results of our study are in accordance with those of studies reporting high-body weight stigma. The annoying and disgraceful look was one of the subthemes in this study. Participant's talks were fraught with words that showed how much these people suffered from annoying and shameful eyes. Some mothers with a high body mass imprisoned themselves at home because of annoying and stigmatizing eyes and they were embarrassed by their presence in the community, which would further inactivate these women and worsen their condition. Discrimination is rejected in every context, and, of course, bias and discrimination due to maternal weight impose further concerns on them. These findings are consistent with Paul and Brownell's findings, suggesting that ant obesity behaviors among health care workers can affect their clinical judgment and prevent the referral of high-body people to care and services[34]. Studies have also shown that high body mass is highly related to physical disabilities [35]. Women with high body mass are more likely to be blamed compared to men with high body mass index, and social stigma with a high body mass affects women more than men; so, discrimination is not just in health matters. It also affects job, social, and educational relationships. Women with high body mass are derived from respect, education, social interactions, and income [36,37].

In this study, mothers with high body mass were found to be very humiliated and blamed for their high weight. According to Malroed et al., with the onset of pregnancy, obesity becomes a particular problem that may cause physical and mental problems [36]. Obesity is associated with depression and anxiety in a non-pregnant population, and pregnant women with high body mass even are suffering from mental problems, sadness, and grief during pregnancy. Depression during pregnancy and postpartum in people with high body mass is much higher than in normal weight subjects. In addition, severe mental and eating disorders and abnormalities in preterm labor are higher in women with high body mass [38]. In some maternal mortality studies, suicide and depression were the major causes of maternal mortality [20]. The weight stigma has a negative impact on the mental and physical health of the victims [33]. Health care providers should consider that women with high body mass are more prone to depression before and after childbirth [38]. Lindhardt et al conducted a qualitative study entitled "Pregnant women with an over 30 BMI" in dealing with their health care providers. Pregnant women with a high body mass index experienced bias from health care providers. These women felt that they were treated with lack of respect and defamatory response, and they felt a sense of lack of useful information [32].

Farber and McGuan conducted a qualitative 
study on women's experiences with BMI over 35 in childbirth through interviewing 19 women. Two sub-themes extracted in this study were humiliation of pregnancy in obese women and medication of obese during pregnancy. In these women, the felt of humiliation and pregnancy stigma with obesity were prominent. Interaction with health professionals and people exacerbated their discomfort sense about their size. Highrisk pregnancies in obese women made them pregnancy more dependent on interventions and medical interventions. Ultrasound was a significant source of annoyance, especially if embryo-imaging problems were not explicitly described in the method. The result is that health professionals should be aware of the psychological consequences of obesity, and communication strategies for care should be clear and honest, and communication must be done in a sensitive manner [39].

The findings of the study of Nyman et al showed that obese pregnant women had negative experiences with their health care. In the care of obese pregnant women, it is necessary to give them time and opportunity to tell their story. Care providers are forced to improve their health, but they must be honest and respectful. Health care providers must be aware of their attitudes and strengths in order to avoid the judgment that causes sufferings to pregnant women with high body mass [40].

Our study, like other qualitative studies, focused on women's pregnancy experiences; the fear of intensifying overweight, humiliation and discrimination, the emergence of chronic diseases, macrosomia, fear of death, worries about the consequences of obesity during pregnancy, the effect of pregnancy on their health, anxiety, and depression were among the most important concerns of these women. Paying attention from health providers to these concerns are very important and valuable.

One of the limitations of the study was the reluctance of high-body pregnant women to participate in research due to lack of time, personal reasons, and fear of disclosure of their name and identity. The researcher tried to explain the goals of research and observe the ethics to gain participants' trust and confidence to overcome these constraints.

\section{Conclusion}

This Hermeneutic phenomenology study showed that having high body mass and pregnancy could cause more worries and vulnerabilities in these mothers. These pregnant mothers need more emotional and social support and failure to paying attention to these important variables could play a role in the failure of interventions to modify behavioral patterns of these vulnerable individuals. It must be noted that physical characteristics should not be a criterion for judgment because a person is beyond the material body, and this body should not affect other aspects of the personality of an obese mother. High body mass women expect health care providers to behave more friendly rather than to blame them and spend more time on their health problems. Therefore, health care providers should be aware of their attitudes and behaviors toward this group of clients and avoid any stereotypical and harassing care behaviors. It is imperative that health care providers know and understand the specific needs of this group of mothers that have acquired from their own living experiences and be able to provide appropriate care to pregnant women with high body mass, and this situation must not deprive them of receiving health care. It should be taken into account that a positive relationship between health care providers and high-body women leads to the search for ways to a proper health care. Further studies are required to explore the social and psychological dimensions of pregnancy in high body mass women.

\section{Acknowledgments}

The author of the paper appreciate the research deputy of Ardabil university of medical sciences for providing research financial supports in the form of research project No.9312, 8 January 2015, as well as the mothers who participating in this study and shared their experiences heartily. 


\section{Contribution}

Study design: SSh

Data collection and Analysis: SSh

Manuscript preparation: SSh

\section{Conflict of Interest}

"The authors declare that they have no competing interests."

\section{Funding}

Deputy research of Ardabil medical university provided the financial support in project No 9312. 2015 January 8 for this research..

\section{References}

1- World Health Organization (WHO), 2014. Available atURL: http://www.emro.who.int/health-topics/obesity. Accessed January 10, 2007.

2- Baeten JM, Bukusi EA, Lambe M. Pregnancy complications and outcomes among overweight and obese nulliparous women. Am J Public Health2001; 91: 436- 40. 3- Anon. Iranian ministry of health and medical education. NCD risk factor Info Base. Available atURL: http://www. ncdinfobase.ir/english/. Accessed January 10, 2007

4- Emamian MH, Fateh M, Hossein Poor AR, Alami A, Fotouhi A. Obesity and its socioeconomic determinants in Iran. Econ Hum Biol2017; 26: 144-50.

5- Cedergren MI. Maternal morbid obesity and the risk of adverse pregnancy outcome. Obstet Gynecol2004; 103: 219-24.

6- Vizeshfar F, Sharifzadeh Z. Assessment body mass index effect on pregnancy outcomes in larian women referred to health center in 2008. The Iranian Journal of Obstetrics, Gynecology and Infertility2011; 14(4): 41-6.

7- American college of obstetricians and gynecologists. ACOG Committee opinion no. 549: obesity in pregnancy. Obstet Gynecol2013; 121(1):213-7.

8- Lashen H, Fear K, Sturdee DW. Obesity is associated with increased risk of first trimester and recurrent miscarriage: matched case-control study. Hum Reprod2004; 19(7): 1644-6.

9- Rasmussen SA, Chu SY, Kim SY, Schmid CH, Lau J. Maternal obesity and risk of neural tube defects: a metaanalysis. Am J Obstet Gynecol2008; 198(6): 611-9.

10- Jacobsen A, Skjeldestad F, Sandset P. Ante-and postnatal risk factors of venous thrombosis: a hospitalbased case-control study. J Thromb Haemost2008; 6(6): 905-12.

11- Larsen TB, Sørensen HT, Gislum M, Johnsen SP. Maternal smoking, obesity, and risk of venous thromboembolism during pregnancy and the puerperium: a population-based nested case-control study. Thromb
Res2007; 120(4): 505-9.

12- Sebire NJ, Jolly M, Harris J, et al. Maternal obesity and pregnancy outcome: a study of 287213 pregnancies in London. Int J Obes2001; 25(8): 1175-82.

13- O'Brien TE, Ray JG, Chan W-S. Maternal body mass index and the risk of preeclampsia: a systematic overview. Epidemiology2003; 14(3): 368-74.

14- Nuthalapaty FS, Rouse DJ, Owen J. The association of maternal weight with cesarean risk, labor duration, and cervical dilation rate during labor induction. Obstet Gynecol2004; 103(3): 452-6.

15-Molyneaux E, Poston L, Ashurst-Williams S, Howard LM. Obesity and mental disorders during pregnancy and postpartum: a systematic review and meta-analysis. Obstet Gynecol2014; 123(4): 857-67.

16- Chu SY, Kim SY, Lau J, et al. Maternal obesity and risk of stillbirth: a metaanalysis. Am J Obstet Gynecol2007; 197(3): 223-8.

17- Kristensen J, Vestergaard M, Wisborg K, Kesmodel U, Secher NJ. Pre-pregnancy weight and the risk of stillbirth and neonatal death. BJOG: An International Journal of Obstetrics and Gynaecology2005; 112(4): 403-8.

18- Cedergren MI. Maternal morbid obesity and the risk of adverse pregnancy outcome. Obstet Gynecol2004; 103(2): 219-24.

19- Shah A, Kenny L, Sands J. Maternal obesity and risk of stillbirth and neonatal death. J Matern Fetal Neonatal Med2006; 19: 88.

20- LaCoursiere DY, Barrett-Connor E, O’Hara MW, Hutton A, Varner MW. The association between prepregnancy obesity and screening positive for postpartum depression. BJOG: An International Journal of Obstetrics and Gynaecology2010; 117(8): 1011-8.

21- Li R, Jewell S, Grummer-Strawn L. Maternal obesity and breast-feeding practices. The American Journal of Clinical Nutrition2003; 77: 931-6.

22-Amir LH, Donath S. A systematic review of maternal obesity and breastfeeding intention, initiation and duration. BMC Pregnancy Childbirth2007; 7(1): 9.

23- Heslehurst N, Ells LJ, Simpson H, Batterham A, Wilkinson J, Summerbell CD. Trends in maternal obesity incidence rates, demographic predictors, and health inequalities in 36,821 women over a 15-year period. BJOG: An International Journal of Obstetrics and Gynaecology2007; 114(2): 187-94.

24- Kanagalingam MG, Forouhi NG, Greer IA, Sattar N. Changes in booking body mass index over a decade: retrospective analysis from a Glasgow Maternity Hospital. BJOG: An International Journal of Obstetrics and Gynaecology2005; 112(10): 1431-3.

25- Polit D, Beck CT. Essentials of nursing research: appraising evidence for nursing practice. USA: Lippincott Williams \& Wilkins; 2010. pp: 610. 
26- Parvizy S, Adib-Hajbaghery M, Salsali M. Principles and methods in Qualitative research. Tehran: Jameenegar; 2015.

27- Van Manen M. Phenomenology of practice: meaning - giving methods in phenomenological reasearch and writing. New York: Routledge; 2014.

28- Knight-Agarwal CR, Williams LT, Davis D, et al. The perspectives of obese women receiving antenatal care: A qualitative study of women's experiences. Women and Birth2016; 29(2): 189-95.

29- Wuntakal R, Hollingworth T. Leptin-a tocolytic agent for the future? Med Hypotheses2010; 74(1): 81-2.

31- Papp MM, Lindsay A, Mariona F, Chatterjee S. Perinatal outcomes in the super obese: a community hospital experience. Obstet Gynecol2014; 123:159-60.

32- Lindhardt CL, Rubak S, Mogensen O, Lamont RF, Joergensen JS. The experience of pregnant women with a body mass index $>30 \mathrm{~kg} / \mathrm{m} 2$ of their encounters with healthcare professionals. Acta Obstet Gynecol Scand2013; 92(9): 1101-7.

33- Mulherin K, Miller YD, Barlow FK, Diedrichs PC, Thompson R. Weight stigma in maternity care: women's experiences and care providers' attitudes. BMC Pregnancy Childbirth2013; 13(1):19.
34- Puhl R, Brownell KD. Bias, discrimination, and obesity. Obes Res2001; 9(12): 788-805.

35- Latner JD, Stunkard AJ, Wilson GT. Stigmatized students: age, sex, and ethnicity effects in the stigmatization of obesity. Obes Res2005; 13(7): 1226-31. 36- Malterud K, Ulriksen K. Obesity, stigma, and responsibility in health care: A synthesis of qualitative studies.Int JQual Stud Health Well-Being2011;6(4):8404. 37- Shahbazzadegan S. Lived experience in obese women: a hermeneutic phenomenological study. 1st community medicine Congress on Non communicable diseases prevention and control. Tehran, Iran. 2017. pp: 370-1.

38- Molyneaux E, Poston L, Ashurst-Williams S, Howard LM. Obesity and mental disorders during pregnancy and postpartum: a systematic review and meta-analysis. Obstet Gynecol2014; 123(4): 857-67.

39- Furber CM, McGowan L. A qualitative study of the experiences of women who are obese and pregnant in the UK. Midwifery2011; 27(4): 437-44..

40- Nyman VM, Prebensen $\AA$ K, Flensner GE. Obese women's experiences of encounters with midwives and physicians during pregnancy and childbirth. Midwifery2010; 26(4): 424-9.

Copyright(C) 2016 ASP Ins. This open-access article is published under the terms of the Creative Commons Attribution-NonCommercial 4.0 International License which permits Share (copy and redistribute the material in any medium or format) and Adapt (remix, transform, and build upon the material) under the Attribution-NonCommercial terms. 